\title{
HISTORIAS CINEMATOGRÁFICAS POCO CONTADAS: CARNE DE FIERAS \& LA PUERTA DEL CIELO (1936-1945)
}

\author{
Rosa María Ballesteros García* \\ SEIM/Universidad de Málaga
}

\begin{abstract}
RESUMEN
Muchas son las coincidencias y también las peculiaridades que confluyen en estas dos extraordinarias producciones que por sí solas merecen nuestra especial atención. Ambos rodajes se iniciaron durante conflictos bélicos, bajo el fragor de los disparos y la explosión de las bombas como fondo del escenario. En ambos casos, y en esto coinciden ambas películas, el fascismo y el nazismo actuaron como telón de fondo y también en su rápida retirada de la cartelera. La película italiana tuvo el gran mérito de haber salvado la vida a varios cientos de personas: judíos, gitanos, antifascistas... La cinta española quedó sepultada en los archivos de la desmemoria del tiempo durante más de medio siglo y lanzó al exilio a varios de sus componentes.
\end{abstract}

PALABRAS CLAVE: cine, guerra, fascismo, nazismo, exilio

*rosaballesterosgarcia@gmail.com 


\title{
CINEMA HISTORIES NEVER COUNTED CARNE DE FIERAS \& LA PUERTA DEL CIELO (1936-1945)
}

\author{
Rosa María Ballesteros García* \\ SEIM/Universidad de MÁlaga
}

\begin{abstract}
There are many coincidences and peculiarities that come together in these two extraordinary productions that, on their own, deserve our special attention. Both shootings started during armed conflicts, with the roar of gunshots and bomb explosions as background. In both cases, as stated in both films, Fascism and Nazism acted as background and had a role in their quick withdrawal from the listings. The Italian film held the great merit of saving the lives of several hundreds of people: Jewish and Romani people, antifascists... The Spanish film remained buried in obscurity during more than half a century, and led several of its components to exile.
\end{abstract}

KEYWORDS: cinema, war, fascism, nazism, exile

Enviado: 03/11/2019

Aceptado: 05/05/2020

*rosaballesterosgarcia@gmail.com 


\section{RODAJES, DOS PAIÍSES... ¿DOS GUERRAS?}

Cine, Historia y Guerra, constituye una tríada de particular interés en el saber contemporáneo ${ }^{1}$.

A través del presente artículo, y como se apunta en el título, vamos a recuperar dos películas que han pasado sin pena ni gloria para la historiografía del género. No son grandes producciones, ni sus protagonistas son estrellas de relumbrón, ni sus argumentos han merecido engrosar la lista de ninguna candidatura $\mathrm{y}$, sin embargo, tienen como atractivo el contexto en que se desarrollan sus rodajes. Podríamos decir que son intrahistorias dentro de la historia misma; historias que, eclipsadas por esa Historia, con mayúsculas, que tiende a minimizar lo cotidiano, nos muestran esas otras miradas que han pasado desapercibidas y que, por ese mismo desconocimiento, merecen ser recordadas porque ellas también son parte de esa Historia.

Muchas son las coincidencias, pero también variadas las peculiaridades que confluyen en estas dos producciones que por sí solas merecen nuestra especial atención y por ello, a través del presente trabajo, nos disponemos, pues, estudiar los aspectos que consideramos relevantes, poniendo en primer plano las intrahistorias que las hacen tan interesantes sin olvidar el contexto social y político de sus rodajes. Partiendo de este aspecto, ambas se realizaron durante sendos conflictos bélicos, bajo el fragor de los disparos y la explosión de las bombas como fondo del escenario. En el caso de la película española, Carne de fieras, se comenzó el rodaje un 16 de julio de 1936; es decir, dos días antes de producirse el Golpe de Estado militar que desencadenó la Guerra (in)Civil española (1936-1939), con todas sus terribles secuelas, y con el item añadido de ser antesala de un conflicto, aún más amplio, en el que se vería envuelto el rodaje de la segunda, la película italiana La puerta del cielo, iniciado en el verano de 1943, en pleno apogeo de la Segunda Guerra Mundial, y finalizado en 1944 tras la entrada de las tropas aliadas en Roma. Fue un largo lapsus voluntario que tenía como objetivo el salvar la vida a unos cientos de extras, judíos en su mayoría, carne irremediable de crematorio.

Esta es una de las peculiaridades, como ya comentamos. Otra coincidencia, si se quiere, es que ambas se realizaron en contextos de terribles tiempos revueltos. La película italiana se rodó durante la última etapa de la SGM, bajo el control de los nazis, si bien entre 1943 y 1945 hubo

1. L. R. RoJAs (1993).

(C) Baetica. Estudios Historia Moderna y Contemporánea, 40, 2020, 335-362. Facultad de Filosofia y Letras, Universidad de Málaga. Departamento de Historia Moderna y Contemporánea 
tropas italianas en ambos bandos del conflicto. En otras palabras, nos encontramos, pues, con otra guerra civil en el marco de la guerra mundial. En ambos casos, y en esto coinciden las dos películas, el fascismo y el nazismo actuaron como telón de fondo en los escenarios y también los espectadores no llegaron a disfrutarlas en su momento. Mejor dicho, y para mayor exactitud, la producción española Carne de fieras durmió un largo sueño de más de medio siglo hasta ver la luz. La puerta del cielo apenas se mantuvo unos días ${ }^{2}$, por causas varias que su patrocinador Orbis Film (Centro Cattolico Cinematografico) esgrimió, tales como su mediocre calidad o su poca ortodoxia religiosa (como parte de su argumento) ${ }^{3}$, aunque también se debió calibrar la relación extramatrimonial que mantenían el director De Sica (1901-1974) y la protagonista femenina, la española María Mercader (1918-2011). Otra de las razones que arguyen algunas fuentes es que lo importante de la película fue su rodaje y no su exhibición. Sobre este asunto el mismo De Sica, su director, escribe: "Una vez liberada Roma, la película La puerta del cielo estaba a punto de proyectarse; sin embargo, no fue del agrado del Centro Católico Cinematográfico, porque no respondía a la ortodoxia puramente católica"4.

Por otro lado, también en ambos rodajes se combinaron profesionales con actores que no lo eran. En el caso español actuaron artistas de variedades, como Marlène Grey, Georges Marck o Jack Sidney junto a actores y actrices profesionales: Alfredo Corcuera, Tina de Jarque o Mercedes Sirvent, entre otros. En el caso italiano, actrices y actores consagrados como María Mercader, Marina Verti, Elli Parvo, Massimo Girotti, Roldano Luppi o Carlo Ninchi colaboraron para que el proyecto se convirtiera en un refugio de muchos extras de nombre desconocido, actores a la fuerza, para salvar la vida en una guerra que sí era la suya. Finalmente, se puede concluir que ambos conflictos bélicos terminaron por ser los de todos, y si bien la crítica cinematográfica concluyó en su momento que no fueron unas buenas películas ${ }^{5}$, la italiana tiene, sin embargo, el gran mérito de haber salvado la vida a varios cientos de personas, como hemos apuntado, y ello es, en nuestra opinión, una excelente razón para que su memoria no

2. La película estaba financiada por el Vaticano, que vetó la distribución de la cinta. Solo se conservan tres copias, dos guardadas en los archivos vaticanos y una tercera en poder de Christian De Sica, hijo del director.

3. Sobre el argumento, veremos la descripción en el epígrafe dedicado a la película.

4. V. De Sica (2015), 95.

5. En el caso de la película de De Sica la crítica ha sido más taxativa al calificarla sin paliativos como "una mala película". 
quede sepultada en los archivos de la desmemoria.

Por otro lado, sobre la importancia y el poder del cine existe una amplia bibliografía que acredita hasta qué punto los dirigentes políticos, al margen de cualquier nacionalidad o ideología, hicieron de este medio un "arma" muy efectiva, como se evidencia en el documental Five came back, presentado en 2017, basado en el libro de Mark Harris: Five Came Back: A Story of Hollywood and the Second World War. Parafraseando al director Frank Capra, que interviene en el citado documental, y que había realizado en su momento cintas similares durante la Segunda Guerra Mundial, se llegó al convencimiento de que a los soldados se les convencía no con discursos, pero sí con el cine.

Hecha esta introducción, mínima, porque pretendemos que "los árboles no impidan ver el bosque", nos concentraremos en los siguientes epígrafes para dar protagonismo a la historia y a los protagonistas de estas dos olvidadas películas del cine internacional ${ }^{6}$.

\section{EL CONTEXTO HISTÓRICO: ESPAÑA, 1936 (BAJO LAS BOMBAS)}

Durante la tarde del sábado, se había rumoreado mucho sobre una sublevación fascista inminente. Pero, a decir verdad, nadie daba crédito a la cosa... 7

Con la llegada de la República el 14 de abril de 1931, las nuevas fuerzas políticas tomaron conciencia de la importancia y la necesidad de elaborar diversas medidas para apoyar el cine nacional, intuyendo el potencial de mercado y valorando al mismo tiempo el inmenso poder de "la linterna mágica" para llegar a todas las capas sociales. Se ha escrito que el cine es el arte de los políticos y de ello tenemos innumerables ejemplos. En opinión de William Hays (1879-1954) ${ }^{8}$, de su control, de su poder "no se puede escapar por su facilidad para llegar a las masas". El cine, pues, se convertiría, prácticamente desde sus comienzos, en uno de los negocios "más colosales de nuestro tiempo" . En este contexto se dieron los primeros pasos

6. Las citas textuales se acompañan de la referencia de la obra, fecha y autoría relacionadas en la bibliografía. En el caso de las citas de web se especifica la fecha de consulta.

7. A. Guerra (2005), 28.

8. Presidente del Comité Nacional Republicano y Director General de Correos de Estados Unidos desde 1921 a 1922, famoso por su célebre código moral.

9. Cfr. "El cine como el arma del poder" en www.tenislosalcazares.com/fgi/cine/cineypoder. pdf (consulta: 15/1/2018). 
para convertir la mediocre industria nacional en un proyecto con futuro, en cuanto al mercado internacional -especialmente el hispanohablante- y a la producción. Por otro lado, como no podía ser de otra forma, los partidos políticos, los sindicatos y hasta los grupos religiosos se pusieron en marcha para crear sus propias redes de salas de cine, cada uno arrimando las ascuas a su "sardina" particular. Los ateneos libertarios, las casas del pueblo, los centros religiosos... Todos ellos procuraron expandir su ideario a través de lo filmado. Sin embargo, este tímido, pero esperanzador, despegue, iba a sufrir un notable estancamiento debido a los acontecimientos que eclosionaron el 18 de julio de 1936. Este es el escenario donde se desarrollan nuestras dos historias; nos referimos, como es lógico, al escenario bélico que enmarca una década ominosa, entre el 18 de julio de 1936, cuando estalla la Guerra Civil española, hasta el 2 de mayo de 1945 en que las tropas soviéticas conquistan Berlín.

En España, los acontecimientos que se desarrollaron en los días siguientes a la rebelión militar iban a determinar no sólo el número de producciones cinéfilas, sino la temática de sus argumentos, todo ello sumado a la huida de empresarios y capitales que abocó al desmoronamiento de la economía. Por otro lado, la industria cinematográfica, ubicada principalmente en Madrid y Barcelona, quedó en manos de los republicanos; por el contrario, el bando golpista, apenas sin infraestructuras, tuvo que recurrir a realizar sus películas en los estudios de Berlín, Roma o Portugal, el país vecino, que venía manteniendo durante los años de la República un no disimulado antagonismo con los gobiernos españoles. El estallido de la guerra cambiará esta tensa relación por una alianza estratégica que se manifestará en muy diversos planos, y en el caso concreto que nos ocupa en una breve pero intensa colaboración cinematográfica, dada la identificación ideológica con los golpistas. La colaboración se materializó en la utilización de los laboratorios lisboetas y la obtención de metrajes de película virgen para montar con mayor prontitud los documentales españoles ${ }^{10}$.

Por otro lado, la producción republicana fue generalmente propagandística, focalizándose en la realización de cortometrajes como España 1936, de Le Chanois y guion de Buñuel; En pie la juventud. Por la independencia de España o España republicana, filmados en 1937. También se llegarían a estrenar películas de ficción: Luis Candelas, de Fernando Roldán, Centinela alerta, de Jean Grémillon y Luis Buñuel, ambas de 1937, o El rayo (1939), de José Buchs. De entre los pocos títulos de ficción que se rodaron desta- 
camos Nosotros somos asi (1936) y La silla vacía de Valentín R. González; La Millona, de Antonio Momplet; Rinconcito madrileño, de León Artola o Nuestro culpable de Fernando Mignone (1937). En la zona republicana el sector cinematográfico quedaría a las órdenes de los sindicatos de la CNT (SIE Films) y del Partido Comunista (Popular Films), con la productora del Gobierno, Laia Films. Recuperamos así nombres de intérpretes olvidados, como Francisco Baena, Polita Bedrós, Laly Cadierno, Ana M. ${ }^{a}$ Custodio, el famoso cantante "Angelillo", Josep Balaguer, Lolita Baldo, José Pal, Dolores Arguimbau, Ana de Leiva, María Cañete o Charito Leonís. En la llamada "zona nacional", prácticamente vacía de infraestructuras, como ya adelantamos, se produjeron documentales como Alma y nervio de España (1937) de Martínez Arboleya y alguna película de ficción como El genio alegre $^{11}$ de Fernando Delgado, realizada en ciudades conquistadas por los sublevados (Córdoba/Sevilla) en los Estudios CEA y CIFESA ${ }^{12}$. Esta última quedó dividida fijando en Sevilla la sección "nacionalista". Las pocas películas de ficción del bando rebelde se produjeron en Alemania con la creación de la productora Hispano Film Produkcion por directores como Benito Perojo o Florián Rey con títulos como Carmen, la de Triana, El barbero de Sevilla o Suspiros de España, con estrellas del momento como Imperio Argentina y Estrellita Castro. En un interesante y bien documentado artículo, Juan B. Heinink hace un resumen de los filmes producidos durante los años del Frente Popular y el fin de la República. Según el autor, se han conservado 12 títulos, algunos estrenados en la postguerra: ¿Quién me quiere a mí?, El bailarín y el trabajador, El deber, La Millona, La Reina Mora, ;Centinela, alerta!, Rinconcito madrileño, El rayo, El genio alegre, María de la $O$, La farándula, Carne de fieras, además de profesionales, hoy prácticamente olvidados, como Leocadia Alba, Concha Catalá, Lolita Astolfi o Antonio Vico ${ }^{13}$.

Por otro lado, el eco de la contienda se plasmaría en producciones internacionales, largometrajes de ficción o documentales. Entre los primeros, destacamos tres producciones made in Hollywood: The last train from Madrid (El último tren de Madrid) de James P. Hogan, una historia coral no partidista, con Dorothy Lamour y Gilbert Roland; Love under fire (Bajo el fuego) de Gorge Marshall, un melodrama detectivesco, con Loretta Young y Don Ameche, ambos estrenados en 1937; Blockade (Bloqueo) de William

11. El Genio alegre acabó de rodarse en 1939 y se estrenó en diciembre de ese año.

12. M. Cruselles (1998).

13. J. B. Heinink (1998).

(C) Baetica. Estudios Historia Moderna y Contemporánea, 40, 2020, 335-362. Facultad de Filosofia y Letras, Universidad de Málaga. Departamento de Historia Moderna y Contemporánea 
Dieterle, un melodrama romántico con la Guerra Civil de fondo, con Madeleine Carroll y Henry Fonda (1938), o L'espoir (Sierra de Teruel), un drama romántico en coproducción con Francia, dirigido por André Malraux, guion del escritor español Max Aub y actores, entre otros, como Andrés Mejuto, Julio Peña, José Sempere o Pedro Codina. Se rodó en Cataluña y fue estrenado en febrero de 1940 por la Cinematheque Française. Finalizada la Segunda Guerra Mundial fue vista en otros países europeos como Bélgica (1945), Holanda y Dinamarca (1946) y también en USA (1947).

\section{CARNE DE FIERAS (DOS "VENUS" EN UNA MISMA HISTORIA)}

Así relata Guerra los prolegómenos del rodaje: "Desde las siete de la mañana hasta la caída de la tarde, había estado rodando exteriores de una película titulada Carne de fieras, en los jardines del Retiro. La película la habíamos empezado el jueves, 16 de julio. Yo era el autor, realizador e intérprete de un papel especial"14.

La película que dirigió Armand Guerra es un melodrama dramático, con un toque romántico, donde se entremezclan historias de amor, circo, celos e intriga en torno a dos parejas; la primera formada por Pablo Álvarez Rubio ("Pablo"), un boxeador casado con una antigua corista: Tina de Jarque ("Aurora"), conocida como La Venus Morena. La segunda pareja la forman un maduro domador de leones Georges Marck ("Monsieur Marck") y su compañera, una espectacular artista de circo: Marlène Grey ("Marlène"), de quien está enamorado su compañero. La pareja trabaja en un número de circo con cuatro leones ante los que baila, desnuda, la Venus Rubia Marlène ${ }^{15}$. Junto a los presentados el ayudante de Pablo, Alfredo Corcuera ("Picatoste"); un extraño personaje: Armand Guerra ("Lucas"), ayudante a su vez del domador y enamorado a su vez de la rubia; un niño, personaje clave de la historia, adoptado por Pablo, y un ama de llaves de Pablo que encarna la actriz Mercedes Sirvent. Y aquí comienzan los celos: Pablo descubre que Aurora le es infiel, pero su reacción, aunque muy tocado, no se traduce en violencia contra la ingrata. Poco después conoce a Marlène (flechazo mutuo) en el Parque del Retiro el mismo día que salva de morir ahogado a un pilluelo que después adopta. Pablo vuelve a encontrarse con Marlène y Marck en un cabaret donde, para su sorpresa, también actúa

14. A. Guerra (2005), 18.

15. Verdadera estrella central de la historia, por ser la protagonista de uno de los primeros desnudos del cine español. 
como bailarina su exmujer -no se comprende como también le acompaña el pequeño, sentado, muy digno, frente a un vaso que intuimos, por el color, de agua o gaseosa-. Allí se inicia la trifulca cuando Marck, celoso porque se ha percatado del enamoramiento de la rubia y el boxeador, le increpa a este y le amenaza de muerte. En la escena siguiente, con fondo trágicamente negro, Pablo es golpeado de gravedad -solo se aprecia el brazo y el instrumento del anónimo agresor-por lo que es ingresado en el hospital. Las sospechas recaen en el amenazador Marck, pero gracias a la astucia del chiquillo adoptado, que ha encontrado una pista, se apresa al verdadero autor que resulta ser el inquietante Lucas, enamorado también de Marlène. En la escena final, un comprensivo Marck da sus bendiciones a la joven pareja (Pablo y Marlène) que forma un trío con el pilluelo, acurrucado entre los dos en la cama del hospital donde Pablo se recupera de la agresión. El amor ha triunfado. El agresor ha sido atrapado. El niño indigente ha encontrado un hogar. El maduro enamorado ha entendido que el amor es para los jóvenes. Final feliz como corresponde a un perfecto melodrama romántico... pero incomprensible dado el contexto social del momento.

La película descrita no llegó a estrenarse. Sus más de 40 rollos resultantes del rodaje desaparecieron durante 56 años hasta que en 1992 se recuperaron fortuitamente. Tras un trabajo de reconstrucción a cargo de Ferrán Alberich y Ana Marquesán, de la filmoteca de Zaragoza, vio de nuevo la luz esta sorprendente película. Su rodaje, como puede deducirse por el contexto, estuvo plagado de interferencias de principio a fin; entre otras, los componentes del equipo de rodaje, casi todos afiliados al sindicato anarquista, iban y venían del rodaje al frente. Los leones, famélicos, a punto estuvieron de comerse a la protagonista, hasta que el sindicato de alimentación de la CNT tuvo que socorrer con sus escasos medios a los animales. Fue la última película de ficción que dirigió Armand Guerra, que tampoco pudo realizar su deseo de rodar una producción sobre el dirigente anarquista Buenaventura Durruti, muerto en noviembre de eses mismo año ${ }^{16}$. Pero aquí no terminan las peripecias. Las protagonistas femeninas, Marlène y Tina (las dos Venus) fueron víctimas de finales trágicos. Marlène, al parecer, murió como consecuencia de un ataque de sus animales. $\mathrm{Su}$ pista se pierde en 1939. Por su parte Tina tampoco tuvo un final feliz, fusilada, según la mayoría de las investigaciones, mientras huía con un

16. El propio Guerra, cuando estalla la rebelión militar, quiso abandonar el rodaje para ir a rodar al frente, pero no se lo permitieron argumentando que había varias familias que dependían de ese trabajo. 
alijo acompañada de un amante anarquista. Por último, su director, Armand Guerra, murió de forma súbita al finalizar la Guerra Civil: recién salido de un campo de concentración y perseguido por la Gestapo fue víctima de un aneurisma, en plena calle en París, ciudad donde se había exiliado.

Algunas fuentes apuntan, y esto se ajusta al fondo de este artículo, que la película Carne de fieras más bien "explora" el nuevo ritmo y similar lenguaje que anuncia el neorrealismo italiano, como las escenas a tiempo real, la naturalidad de los diálogos, los personajes reales, el costumbrismo, sus personajes marginales, etc. Las censuras y los silencios, las dictaduras, en suma, forjaron esta forma de hacer cine. Parafraseando al profesor Gubern, su rodaje se aproximó excesivamente a las balas y los obuses. En memoria de aquellos terribles años, y de aquellos intrépidos cineastas, en 2010 los Premios Goya llegaron a nominar al mejor cortometraje documental El cine libertario: cuando las películas hacen historia, de José M. ${ }^{a}$ Almela y Verónica Vigil ${ }^{17}$.

\subsection{El director: Armand Guerra}

Destrozado, desesperado, agotado como muchos de tus compañeros, eras un vencido, y tú el valiente, el rebelde, no soportaste la derrota. Y "tu nena", como me llamabas, no volvió a oír hablar más de ti ${ }^{18}$.

Iniciamos el epígrafe con las palabras de Vicenta Estivalis, hija de nuestro director, un valenciano de nombre José Estivalis Cabo, personaje en verdad polifacético como escritor, tipógrafo, cineasta, periodista, actor y también como un ser humano sensible como padre, esposo y comprometido con unas ideas que lo acompañaron hasta el final, cuando la muerte le sorprendió en su exilio parisino, en plena calle. También políglota, fue corresponsal en Francia de la revista de cine Popular Film y traductor de la obra Sobre la tierra del fuego (1929) del capitán expedicionario alemán Gunter Pluschow. Publicó artículos con los pseudónimos de Cantaclaro, Armand Guerra o Silavitse.

José Estivalis nació en la valenciana Liria en 1886. Sus padres eran campesinos y tuvieron otros hijos. De chiquillo, como otros muchos chavales

17. Cfr. D. S. Serrano, Canichu: fraternidaduniversal.blogspot.com/.../armand-guerrarenaciendo-de-la-metralla.html. En esta edición el ganador fue el corto documental Memorias de un cine de provincias (de Ramón Margareto) y los otros dos finalistas: El pabellón alemán (de Juan Millares) y Un dios que ya no ampara (de Gaizka Urresti).

18. A. Guerra (2005), 7. 
despiertos, fue monaguillo y llegó a ingresar en un seminario, aunque lo abandonó, como tantos otros "apóstoles" laicos, para transformarse en un convencido anticlerical. Sus primeros trabajos fueron como tipógrafo en Valencia, entrando a formar parte de la "aristocracia obrera"19. Participó, como era natural, de las huelgas comandadas por la CNT, sindicato del que entró a formar parte, así como de protestas y manifestaciones, como las surgidas por el caso de la prisión y posterior ejecución del maestro librepensador Francisco Ferrer y Guardia en 1909. Él mismo sufrió prisión y se exilió en Suiza y Francia, contactando con círculos anarquistas. Pero su periplo no finalizó en estos países, también viajó, amparado por sus compañeros, por Italia, Egipto, Atenas, Constantinopla, Constanza, Belgrado o Salónica.

Sus escritos comienzan a publicarse en diferentes medios ácratas, como la barcelonesa Tierra y Libertad, así como en otras publicaciones en francés e italiano, como Le Reveil o Il Risveglio o en traducciones anarquistas del alemán y del francés. Su aproximación al mundo del cine fue en París, en la productora Lux Film Paris, entre otras. Actuó, dirigió y colaboró en la creación de la cooperativa Le Cinéma du Peuple y en las películas Les misères de l'aigille, Le vieux docker o La commune, todas de 1914, o Un grito en la selva (1913). En Berlín trabajó para la UFA en el filme Ein Sommernachtstraum (1925), junto a su buen, y también ácrata amigo, Alexander Granach ${ }^{20}$ o en El amor solfeado (1930), una coproducción Francia-España-Alemania, con Imperio Argentina, Julia Lajos y la cantante y actriz francesa Odette Florelle. Todo ello combinado con mítines políticos, como los efectuados en la fiesta del $1 .^{\circ}$ de mayo de 1914 en París ${ }^{21}$. Dirigió a actrices como Josefina Francés, Imperio Argentina, Julia Lajos,

19. Muchos de los fundadores de los primeros núcleos internacionalistas en España pertenecían al gremio de los tipógrafos que serán conocidos como la "aristocracia obrera" por su cercanía al mundo de la cultura y de las noticias de actualidad.

20. Alexander Grannach (1883-1945) fue un actor de teatro y cine mudo entre 1920-1930. De origen judío, era originario de Austro-Hungría. Cuando Hitler subió al poder tuvo que exiliarse. Vivió en Rusia y posteriormente se instaló en Hollywood. Publicó una autobiografía: There Goes an Actor (1945), se reeditó en 2010 con un nuevo título, From the Shtetl to the Stage: The Odyssey of a Wandering Actor.

21. Armand Guerra desempeñó todo tipo de trabajos en el cine no sólo como director, también fue guionista, actor, director de carteles de diálogo, traductor, productor, tramoyista... En las décadas de 1910-1920, durante la época del cine mudo, había trabajado con figuras tan conocidas como los franceses Sebastián Faure, Jean Grave, André Girard, Laisant, Pierre Martín, Yves Bidamant o Marcel Martinet, y en los años 20 en la UFA con Murnau, Fritz Lang, Hans Newmann, Werckmeister, Granach, Erich Mühsam o el anarquista Rudolf Rocker. 
Florencia Bécquer, María Corda, Lina Clamour, Charlotte Ander, Valeska Gert, Tamara Geva o Musidora, entre otras.

En su faceta de cineasta trabajó en nuestro país en varias películas durante la época del cine mudo: El crimen del bosque azul, La zarpa del paralítico o La maldición de la gitana (todas de 1918); Luis Candelas o El bandido de Madrid (1926); Batalla de damas (1927), coproducción España-Alemania, con Georg Alexander y María Corda y en películas habladas como La alegría que pasa (1934). En 1917 llegó a crear su propia productora, Cervantes Film, colaborando con su amigo Fernand Desprès, antiguo redactor de La Bataille Syndicaliste.

Su pacifismo y antimilitarismo fueron causa de su expulsión de Francia en 1915, si bien era desde años atrás vigilado por sus actividades contestatarias, por su labor activista y por sus artículos en la prensa libertaria, por ejemplo, en la francesa Tierra y Libertad y en publicaciones de otros países, como España, donde tras la Semana Trágica de 1909 en Barcelona los periódicos anarquistas fueron prohibidos.

Cuando estalla la Guerra Civil española, participará fundamentalmente en reportajes en el Frente. Al final de 1936, la CNT necesitaba su talento oratorio y Guerra, disciplinado sindicalista, abandonó las filmaciones para dedicarse a otro arte, el de la oratoria. Conferenciante brillante, Armand Guerra ya había demostrado su habilidad dando mítines en París, como hemos apuntado: la ciudad donde se exiliaría al acabar la guerra tras pasar por un campo de concentración. Falleció en París a causa de un aneurisma, en 1939, cuando se dirigía a la embajada para obtener documentación que lo acreditara, pues por no tener, no tenía ni siquiera documentos de identidad encima. Cuando los nazis invadieron el sur de Francia, su compañera, que vivía en Perpignán, hizo desaparecer los últimos escritos que le quedaban. Aún muerto, temía que su pasado anarquista (había vivido durante más de diez años en Alemania) pudiera ser causa de represión para la familia.

\subsection{Los intérpretes}

Entre los intérpretes que intervinieron en el filme destacamos a Pablo Álvarez Rubio (1900-1983), un actor madrileño que se inició en el teatro como galán de comedia en varias Compañías: las de María Guerrero, Josefina Díaz y Santiago Artigas o María Gámez y Juan Bonafé, entre otras. Pero como él mismo confesaba, su mayor ilusión era hacer cine y gracias a un familiar establecido en EE. UU. pudo al fin trabajar en Hollywood en películas como Monsieur Le Fox (1930), dirigida por Roberto E. Guzmán, 
Hal Roach o Drácula (1931) de George Melford, si bien ya había intervenido en España en películas mudas, entre otras, El puñao de rosas (1923) o Rejas y votos (1925), ambas de Rafael Salvador. A su vuelta a nuestro país intervino en el cine durante los años de la República en películas como El cura de aldea de Francisco Camacho o Una mujer en peligro de José Santugini, ambas en 1936. Tras finalizar la Guerra Civil actuó en varias cintas: la controvertida Raza (1941)22, El verdugo (1948) de Enrique Gómez, basada en una obra de Balzac ${ }^{23}$, o la patriótica Alba de América (1951) de Juan de Orduña, con Amparo Rivelles y Antonio Vilar.

Marlène Grey (¿?-1939) fue una actriz francesa de la que apenas tenemos datos. La prensa la anunciaba como la Venus Rubia y trabajaba de actriz circense. Sabemos a través del libro autobiográfico de Guerra que tras finalizar el rodaje en Madrid salió para Francia, donde al parecer siguió haciendo campaña a favor de la causa republicana. Citando las palabras del director, se despidió de él diciendo: "Salud y pronto triunfo os deseamos de todo corazón!"24. Las diversas fuentes no se ponen de acuerdo sobre la fecha y las circunstancias de su muerte (se dice que atacada por sus leones), aunque se suele citar Marsella como la ciudad donde se produjo el óbito. Sobre ella escribe el periodista de Crónica: "los espectadores, aun los más escépticos, no tienen más remedio que contener la respiración. En realidad, ella atraería igualmente al público con sólo exponer sin velos el prodigio de su cuerpo"25. Marlène estaba casada con Jack Sidney, un actor circense que se metía en el papel de "El hombre autómata" y que intervenía con un pequeño papel en el filme ${ }^{26}$.

22. Con guion del propio Francisco Franco (como Jaime de Andrade) con Sáenz de Heredia y Antonio Román, y protagonizada por Ana Mariscal y Alfredo Mayo. En 1950 se estrenó una nueva versión titulada El espíritu de una raza.

23. En 1963 se rodaría, dirigida por Luis G. Berlanga otra película con el mismo título, si bien los argumentos son bien distintos. En 1948 el argumento versaba sobre un grupo de jóvenes franceses que, huyendo la Guerra se refugian en España. En el segundo caso, una de las joyas del cine español, es un drama que tiene como protagonista a un verdugo que, llegado el caso de intervenir, trata de evadir, horrorizado, su cometido. Entre sus protagonistas: José Isbert y Emma Penella.

24. A. Guerra (2005), 40.

25. Crónica, 28/6/1936, 9.

26. En el libro del profesor Ríos Carratalá (2010) se recoge que el 23 de agosto, antes del regreso a su país, Marlene Grey y los leones de Georges Marck actuaron en un festival pro-heridos de guerra organizado por la CNT en la Plaza de Toros de Madrid. Junto a ellos se anuncian también las vedettes Tina de Jarque y Laura Pinillos, la cupletista cómica Amalia de Isaura, los caricatos Lepe y Alady, el cantante Angelillo y la niña prodigio Antonieta Barbosa Martí, conocida como "la Shirley Temple española". 
Tina de Jarque (1906-1937), o Constantina de Jarque Santiago, conocida como la Venus Morena fue una cantante y actriz internacional española, muy popular como vedette en las primeras décadas del siglo XX. Trabajó en el cine alemán (Bigamia, 1927, de Jaap Speyer), y también en Brasil y Cuba, países de donde se trajo los nuevos ritmos, y en el cine español en películas como La medalla del torero (1922) de José Buchs o Carne de fieras (1936). Como sus anteriores compañeros, perteneció a una familia circense. Tuvo problemas con la censura porque fue una de las pioneras del destape. Hablaba cuatro idiomas, cantaba varios géneros y practicó el naturismo. Entre sus amantes se cuentan el famoso boxeador Paulino Uzkudun y el millonario Juan March. Los biógrafos no se ponen de acuerdo en cómo murió. Se dice que fue fusilada por espía o porque intentaba fugarse de España, junto a un joven anarquista y un botín de joyas. Al parecer, el hecho tuvo lugar en Valencia, y hay quien afirma que logró llegar a Francia. Pero de ella no quedó rastro.

Alfredo Corcuera fue un actor español que intervino en películas mudas: La Verbena de la Paloma (1921) de José Buchs o Estudiantes y modistillas (1927) de Juan A. Cabero, entre otras; durante los años de la República intervino en La musa y el fénix de Constantin J. David o Rosario la Cortijera de León Artola, ambas de 1935. Posteriormente, cuando finalizó la Guerra Civil se trasladó a México, trabajando en los filmes: $L a$ niña de mis ojos (1947) de Raphael J. Sevilla, Aventuras de Cucuruchito y Pinocho (1943) de Carlos Véjar Jr. o El hijo de Cruz Diablo (1941) de Vicente Oroná. Coincidió allí con otros actores exiliados: Antonio Bravo, Enrique García Álvarez, Luis Mussot, Paco Martínez, Maruja Grifell, José Pidal o la malagueña Alicia Rodríguez; con directores como Carlos Véjar o Francisco Jambrina y guionistas como Salvador Bartolozzi o Magda Donato.

Georges Marck trabajó en el circo de domador de leones. Fue también un actor francés de cine mudo y hablado. Intervino en películas francesas como el drama Le coeur d'un gosse (1913) de Emile Chautard o La venenosa (1928) de Roger Lion, basada en la novela Homónima de José M. ${ }^{a}$ Carretero, protagonizada por Raquel Meller. En 1936 intervino en Carne de fieras, en su papel de domador circense. Existe alguna información que lo asocia con George J. Marcksu (se cree que fue su padre), también actor del cine mudo. Primero en el Circo Price y luego en el Teatro Maravillas presentaron el número circense que representaba junto a Marlene. En el reportaje de Crónica, firmado por Rafael Martínez Gandía, titulado Una mujer desnuda entre cuatro leones, el articulista realiza un sustancioso artículo de la troupe, donde cita al domador como "protector" de Marlene en los siguientes términos: 
Georges Marck es el domador. Puede mostrarles cicatrices en el lugar del cuerpo que ustedes prefieran. Marck, mientras Marlene baila, vigila los menores movimientos de las fieras. Pero si algún día una de éstas se enfada, no sé hasta qué punto será eficaz la ayuda del veterano domador ${ }^{27}$.

\section{EL CONTEXTO HISTÓRICO: ITALIA, 1943-1944 (BAJO LA BOTA NAZI-FASCISTA)}

Combatientes de Tierra, del Mar y del Aire, Camisas Negras de la Revolución y de las Legiones, hombres y mujeres de Italia, del Imperio y del Reino de Albania, ¡escuchen! Una hora señalada del destino se bate sobre el cielo de nuestra patria. Es la hora de las decisiones irrevocables. La declaración de guerra ya ha sido consignada a los embajadores de Gran Bretaña y Francia (Benito Mussolini: 10/6/1940).

Cuando se inicia el rodaje de la película La puerta del cielo Italia se encontraba inmersa en los horrores de la Segunda Guerra Mundial. Durante el transcurso del conflicto los vaivenes políticos tuvieron dos fases bien diferenciadas. A partir de junio de 1940 el dictador, Benito Mussolini, se posicionó al lado de la Alemania nazi de Hitler contra los países aliados ${ }^{28}$, tras firmar el Pacto Tripartito, más conocido como el Pacto del Eje BerlínRoma-Tokio. A partir del derrocamiento de Mussolini, en el verano de 1943, el rey Víctor Emmanuel III y su nuevo gobierno firmaron un armisticio con los aliados, si bien los alemanes seguían controlando gran parte del país con una república títere (República Social Italiana) presidida por Mussolini $^{29}$, un personaje ciertamente controvertido que, desde posiciones socialistas, llegó a liderar el movimiento fascista italiano, a pesar de tener una amante y mecenas judía, Margherita Sarfatti. Líder carismático y ejemplo de la "absoluta virilidad", ejerció un extraordinario magnetismo sobre las masas, especialmente entre las mujeres, y no sólo de las clases populares.

27. Crónica, 28/6/1936, 9.

28. En principio Francia, Reino Unido, Polonia e Irlanda del Norte; posteriormente se les agregaron miembros de la Commonwealth, entre otros, Canadá, Australia o Nueva Zelanda. En 1940 se incorporaron la Francia Libre, Dinamarca, Noruega, Bélgica, Luxemburgo, los Países Bajos, Grecia y Yugoslavia, y, finalmente, en 1941 Rusia (junio) y EE. UU. (diciembre) y poco después China y algunos países de América del Sur.

29. En realidad, aunque teóricamente era Mussolini quien ostentaba el poder, en la práctica eran oficiales de alto rango alemán como el general Karl Wolff o el embajador Rudolf Rahn quienes tomaban las principales decisiones. 
Clementine Churchill, cuando le fue presentado en 1926 lo consideró "uno de los hombres más maravillosos de nuestro tiempo"30; lady Ivy Chamberlain o lady Sybil Graham fueron también admiradoras incondicionales de Il Duce, si bien hay que decir que también tuvo enemigas, como es el caso de Violet Gibson, una excéntrica aristócrata irlandesa que intentó asesinarlo, sin éxito, durante uno de sus incendiarios discursos en abril de 1926. Fue este uno de la serie de atentados dirigidos contra el dictador. Como se sabe, Mussolini fue ajusticiado por los partisanos el 28 de abril de 1945 junto a su amante, Clara Petacci.

Ya avanzada la guerra, la situación política entre 1943 y 1945 evidenciaba que había tropas italianas en ambos bandos del conflicto, lo que vendría a desembocar en una guerra civil dentro del conflicto mundial. Finalmente, el ejército alemán en Italia se rindió el 2 de mayo de 1945 y algunos cineastas, como reacción en aquellos momentos de posguerra y mostrando su rechazo al cine histórico y musical impuesto por el fascismo, se embarcan en un nuevo modo de hacer cine, un género al que se conoció con el nombre de Neorrealismo, término acuñado por el crítico Umberto Barbaro y que tiene a Roberto Rossellini como director de la primera película de este género: Roma, città aperta (Roma, ciudad abierta) realizada en 1945, con argumento basado en la historia real de un sacerdote, Luigi Morosini, torturado y asesinado por los nazis por ayudar a la Resistencia. La acción se desarrolla en Roma, en los últimos años de la ocupación nazi: 1943 y 1944.

El neorrealismo italiano se planteó el objetivo de mostrar al gran público las condiciones sociales más auténticas, el lado más humano de la sociedad italiana, como adelantamos, estando muy alejado del estilo impuesto por el fascismo. Algunas de sus señas de identidad serían la utilización de actores no profesionales y la utilización de escenarios abiertos y urbanos. En esa línea, las producciones ácratas del cine español de los años 30 toman también como modelo ese cine social, descartando el modelo soviético, muy criticado por la mitificación de las masas, por su reiterado culto al liderazgo y, muy especialmente, por el sometimiento a la dura censura. Por otro lado, y desde un punto de vista cronológico, esta nueva arte de hacer cine (neorrealista) apenas se mantuvo una docena de años despegando, como apuntamos, con Roma, città aperta de Rossellini, y culminando su ciclo con Le notti bianche de Visconti en 1957. De la etapa neorrealista queremos destacar al escritor y guionista Cesare Zavattini (1902-1989), uno

30. F. Stonor Saunders (2011), 12. 
de sus principales teóricos, y su Roma, ore uncici (Roma a las 11, 1952) película sobre el drama del desempleo femenino, con argumento basado en hechos reales: doscientas jóvenes se habían amontonado en una escalera atraídas por una oferta de trabajo, hecho que tuvo como consecuencia la rotura del pasamanos y la caída de las mujeres, causando varias heridas y la muerte a una de ellas.

En los años 50 Italia resurgía de sus cenizas. La Democracia Cristiana había llegado al poder en 1948 dando por finiquitada, como se ha escrito, "la era posbélica del romanticismo antifascista militante". El recelo por "airear" las denuncias sociales abocó a reforzar la censura con todo un programa de protección económica a la producción, con el fin de propiciar el viraje del cine pesimista posbélico. Comenzaron a aparecer grandes productoras y las películas fueron más comerciales. Triunfó un cine post-neorrealista con directores como Federico Fellini, Luchino Visconti o Michelangelo Antonioni, por citar los más populares.

\subsection{La puerta del cielo (verano, 1943-verano, 1944)}

De Sica, director de la película, siempre fue un verso libre que huía tanto del comunismo como de los dogmas políticos del fascismo. La verdad es que el filme fue un abrigo protector ante nazis y fascistas. En el verano de 1943, De Sica recibió dos ofertas irrechazables: una, por reclamo del todopoderoso Josep Goebbels, ministro de Propaganda de Hitler, quien pretendía rodar una película en Praga ${ }^{31}$. La segunda oferta, otro caramelo envenenado para el independiente Vittorio, se lo ofrecía el gobierno títere de los nazis en el norte de Italia, también conocido como Reppublica di Salò (localidad de la provincia de Brescia) donde residían todos los líderes nazi-fascistas. Realmente no era un ofrecimiento amable, sino una orden imperiosa: tenía que hacerse cargo de los nuevos estudios de cine fascistas ubicados en Venecia. Así se lo hizo saber el entonces ministro de Cultura Popular Ferdinando Mezzasoma (1907-1945)32. La solución, ante ambos dilemas, fue una carambola propiciada por el Vaticano. El propio De Sica

31. En 1933 su ministerio se hizo cargo de la supervisión de todos los medios de comunicación: radio, prensa, especialmente el cine, por su capacidad propagandística. Furibundo antisemita, no obstante, dos de sus mentores en la Universidad de Heidelberg, donde había estudiado literatura eran judíos: Friedrich Gundolf y el director de su tesis, Max Freiherr von Waldberg.

32. Capturado por los partisanos hacia el final de la guerra, fue fusilado en Dongo el 28 de abril de 1945 junto a una docena de dirigentes fascistas. 
confesaba años después que estaba aterrado ante tan delicada (y dual) situación y entonces recordó que su compañera sentimental, la actriz española María Mercader, iba a protagonizar una película, por encargo del Vaticano, supervisada por el delegado de la producción, Giovanni Battista Montini (el futuro Pablo VI), que entonces trabajaba en la Secretaría de Estado. La película se iba a llamar La puerta del cielo. Vio con ello De Sica el cielo abierto, y no tuvo otra ocurrencia que anunciar a sus posibles "clientes" que ya estaba comprometido en la dirección de la película citada y que tenía que terminarla (no era causa de enemistarse con el Santo Padre). No era cierto, pero la Mercader, fingiendo caprichos de diva, exigía que De Sica la dirigiera -si bien en principio se había pensado en el pintor y director Esodo Pratelli-, cosa que ocurrió y salvó a nuestro director del gran "marrón" que suponía cualquiera de las dos anteriores propuestas.

La acción de la película La puerta del cielo, la sexta película que dirigía De $\mathrm{Sica}^{33}$, se desarrolla en un tren hospital que se dirigía a Loreto, buscando un milagro. Entre los lisiados se encontraban un pianista manco, un huérfano paralítico y un obrero ciego por un accidente. La película pasó sin pena ni gloria apenas unos días en cartelera y las críticas poco halagüeñas aceleraron su retirada de las salas. Por otro lado, la visión irónica y poco ortodoxa del gran milagro final que organizaron, mano a mano, el director De Sica y su guionista Zavattini, tan genial como ateo, espantaron al Vaticano, todo ello con el agravante de la relación adúltera que mantenían director y protagonista. Como consecuencia, al igual que había ocurrido con la producción española Carne de fieras, se hicieron desaparecer todas las copias (menos unas latas olvidadas en los archivos vaticanos). La película fue producida por Orbis, en manos del Centro Católico Cinematográfico, que también produjo algunos documentales en los que se mostraba la labor asistencial, secreta pero eficaz, apadrinada por el papa Pio XII. Su rodaje se dilató hasta que los aliados entraron en Roma en junio de 1944. La puerta del cielo pudo verse en los cines españoles en $1953^{34}$. Se estrenó en Madrid, en el cine Rialto, y la prensa nacional presentaba a María Mercader como la esposa de Vittorio, sin concretar.

33. De Sica ya había dirigido títulos como Madalena... zero en condotta (1940), película en la que intervenía la actriz española Mimí Muñoz, con la que tuvo una hija, también actriz: Vicky Lagos. Mimí fue madre de las actrices Mara, Conchita y María José Goyanes.

34. Se pudo ver en Francia en 1948 y en EE. UU. y Portugal en 1949. 
Ciertamente, se habían casado en México un año antes, por lo civil, pero era una unión ilegal a los ojos de la entonces puritana y clerical España ${ }^{35}$.

\subsection{El director: Vittorio de Sica (el Schindler italiano)}

El director de películas tan memorables como Sciuscià (El limpiabotas, 1946), Ladri di biciclette (Ladrón de bicicletas, 1948) o La ciociara (Dos mujeres, 1960), Vittorio Domenico Stanislao Gaetano Sorano De Sica (1901-1074), hijo de calabrés y napolitana, fue un actor y director de cine italiano ganador de cuatro premios Óscar ${ }^{36}$.

Igual que tantos otros, se inició en el teatro: "entró en el arte", como él mismo apunta en sus memorias, bajo la dirección de la rusa Tatiana Pavlova, de meritorio. Con su compañía viajó por primera vez fuera de Italia rumbo a Buenos Aires. De aquella época, de escasez y bohemia, De Sica nos ilustra cumplidamente con sabrosas anécdotas; anécdotas de la vida cotidiana de él y de sus compañeros de oficio, así como de otros pormenores relacionados con el contexto político del momento, como cuando se refiere a la obligatoriedad de afiliarse al Partido para poder actuar en el Teatro Argentina, a cuyas representaciones acudían, a menudo, Mussolini y Galeazzo Ciano, el yernísimo del Duce, o narra anécdotas asociadas a la pacata censura, la doble versión de las escenas sexuales, por ejemplo aquélla en la que tenía que besar a una bellísima actriz siciliana, Elena Lunda (1901-1947). En las pantallas italianas la besaba en la boca, pero en las versiones extranjeras lo que besaba eran sus pechos. Un caso paralelo, esta vez del cine español, lo tenemos en El último cuplé (1957). En la escena censurada en su momento, un aristócrata ruso (ebrio) trata de besar los pechos de la cantante, papel que interpretó Sara Montiel, a quien también se le tachó alguna estrofa del famoso cuplé "Fumando espero".

Vittorio de Sica viajaría de nuevo a Buenos Aires, esta vez con la compañía de la gran Italia Almirante, con papeles más relevantes. En 1927 conocería a la que fue su primera mujer, la actriz Giuditta Rissone, de la que se separaría años después, cuando conoció a María Mercader y con la que tuvo una hija, Emi, nacida en 1938. En 1930, De Sica deja de actuar

35. La pareja tuvo que repetir en 1968 la ceremonia; esta vez en San Marino, tras renunciar De Sica a la ciudadanía italiana y así poder divorciarse de su primera mujer y evitar de este modo una posible denuncia por bigamia en Italia.

36. A saber: El limpiabotas (1946), Ladrón de bicicletas (1948), Ayer, hoy y mañana (1964) y El jardín de los Finzi-Contini (1971). 
en el Argentina, no renueva la tarjeta del Partido y forma nueva compañía con la Rissone y el actor Umberto Melnati. Aquel año, recuerda, le toca la lotería y, loco de contento, lo celebra con toda su familia, a la que estaba muy unido, especialmente a su padre, al que adoraba. Despega también como actor de cine hablado en la película La vecchia signora (1932) de Amleto Palermi, si bien antes había aparecido en algunas producciones del cine mudo como La compagnia dei matti (1928) y La bellezza del mondo (1927), ambas de Mario Almirante, o El proceso Clémenceau (1917) de Alfredo de Antoni. Durante su vida profesional intervino de actor en unas 160 películas y en decenas como director, autor o productor. También fue cantante, otra de sus facetas en el mundo de las artes escénicas. Como alguien ha escrito, citando una obra de Pirandello: "De Sica fue uno, ninguno y cien mil".

En 1942 trabajó bajo la dirección de Carlo Bragalia en la comedia Se oi fosse onesto (Equívoco feliz) con su futura mujer, María Mercader, y ese mismo año, como director, vuelve a trabajar con ella en Un garibaldino al convento (Recuerdo de amor); al año siguiente, la pareja coincide en las películas Non sono superstizioso... ma! de Bragaglia, y I nostri sogni de Cottafavi. No serán las últimas en las que seguirán coincidiendo, y con María como actriz dirige la llamada trilogía de las denominadas "muchachas en flor", que Vittorio convierte en heroínas: la citada Recuerdo de amor, Madalena... zero in condotta y Nacida en viernes (las dos últimas de 1940 y 1941).

Finalizada la guerra Vittorio y María, a propuesta de Giuseppe Amato, que había sido su productor en La rosa escarlata (1940) y financiado Humberto D. (1952) les invita a viajar a España para rodar una película que el actor dice no recordar bien en sus memorias. Al parecer no interesó el proyecto y se volvieron como llegaron: con los bolsillos vacíos. Así lo recuerda De Sica:

Por la noche llegamos a Barcelona, y antes de entrar en la ciudad, Amato quiso poner al volante para hacer su entrada triunfal en esa ciudad. Llegamos cerca de las diez de la noche al Gran Hotel de Barcelona. No había ni un alma. Tuvimos que llamar al botones del hotel y esperar un buen cuarto de hora ante de que viniese ${ }^{37}$.

De todo el extensísimo currículo fílmico de Vittorio destacaríamos, especialmente, dos títulos: Umberto D. (1952), como director, y El general de la Rovere, realizada en 1959 por Roberto Rossellini, La primera, 
rabiosamente neorrealista, basa su argumento en un jubilado que intenta sobrevivir con su miserable pensión. Sólo tiene dos amigos: la criada de la fonda y su perro Flike, nombre con el que quiso honrar la memoria de su padre y de su perro. En la segunda, como actor protagonista, dio vida a un estafador de poca monta que acepta hacerse pasar por un general badogliano ${ }^{38}$. De Sica hace un extraordinario trabajo haciendo creíble que un individuo amoral, sin principios, se convierta en un héroe antinazi. Actor internacional, sus personajes han pasado desde el héroe al villano; de Príncipe de la Iglesia a aristócrata. En España protagonizó el cuarto de los títulos de la serie: Pan, amor y... junto a Carmen Sevilla. Como el director músico de una banda dio vida al profesor Carotenuto en Pan, amor y Andalucía (1958) ${ }^{39}$.

Comprometido con su tiempo, libre, no dudó en acoger en su casa a refugiados judíos que se escondían de los nazis, detalle revelado por su hijo Christian. Tampoco dudó en renunciar a su nacionalidad para poderse casar con María Mercader, la rubia catalana que había renunciado a su carrera por él y le había dado dos hijos. Su última aparición pública fue en Madrid, donde había viajado con María para inaugurar un cine en el que se proyectó Umberto D., la película que Vittorio quiso dedicar a su padre, como afirma en sus memorias. Murió unos días después, en París, el 13 de noviembre de 1974. Tenía 73 años.

\subsection{La protagonista: María Mercader (1918-2011)}

La catalana María de la Asunción Mercader Fardada (María Mercader para el cine) ya había hecho sus primeros pinitos en el cine español cuando, escapando de los horrores de la Guerra Civil abandonó Barcelona en 1938 bajo las bombas italianas. Había debutado en la película musical Molinos de viento, rodada en 1937 bajo la dirección de Rosario Pi, una de las primeras guionistas y directoras de cine en España y estrenada en $1938^{40}$. Las

38. Pietro Badoglio (18771-1956) fue un militar nombrado por el Rey Presidente del Consejo de Ministro tras la deposición de Mussolini y el armisticio del 8 de septiembre de 1943.

39. Tras Pan, amor y fantasía (1953) llegarían Pan, amor y celos (1954), ambas junto a Gina Lollobrigida, y Pan, amor y... (1955), con Sophia Loren.

40. Junto a Vittorio fundaron una saga artística. Sus hijos Manuel (1949), músico, casado con la actriz y productora Tilde Corsi y Christian (1951), actor y director, casado a su vez con la actriz y productora Silvia Versone. Su nieto Brando (1983), hijo de Manuel, es también escritor, actor y director. 
fuentes suelen afirmar que María se fue a Francia en compañía de Rosario Pi; sin embargo, siguiendo sus memorias, ella afirma no recordar nada de la película dirigida por Pi, "aparte del título". Es más, una vez instalada en París, donde había llegado a instancias de su madre y con la ayuda de un coronel republicano "de buen corazón" que, por lo que deducimos del texto, se había convertido en amante de su madre ${ }^{41}$, ella habría rechazado la propuesta de dar el salto para trabajar con la Fox en Hollywood, como le aconsejaba su antigua directora, convertida ahora en agente cinematográfico. Según María Mercader, fue ella misma la que convenció a esta agente de ir a Italia, cosa que hizo "un mes después de encontrarme yo en Roma"42.

En plena Guerra Mundial, con Italia bajo la bota nazi, la actriz viajó a la España franquista para protagonizar la comedia Madrid de mis sueños (1942), una coproducción hispano-italiana dirigida por Max Neufeld y Gian Maria Cominetti y guion compartido con la también actriz Anita Farra. Ya había conocido a Vittorio de Sica, según confesaba muchos años después en una entrevista en TVE, el que llegaría a ser su marido: mujeriego, jugador, machista y celoso (como ella reconoce en sus memorias). Este no dejaba de enviarle cartas durante el rodaje en las que le declaraba no poder vivir sin ella hasta el punto de llegar al suicidio si la actriz no regresaba. Había conocido al actor durante el rodaje en 1940 de Rose scarlatte ( $\mathrm{La}$ rosa escarlata). Volverían a coincidir en 1942 en la película dirigida por Vittorio Un garibaldino al convento (Recuerdo de amor). De Sica, era un hombre casado desde 1937 con la actriz Guiditta Rissone, con la que tenía una hija, Emi, y otra hija (no reconocida) habida con la actriz española Mimí Muñoz en 1938 cuando esta trabajaba en Italia. Mimí fue madre a su vez de las actrices Mara, María Jesús y Conchita Goyanes. La hija de ambos es Amelia Victoria (Vicky Lagos para el cine). Cuando Vittorio y la Mercader se conocieron había una diferencia de 17 años entre ellos ${ }^{43}$.

Para María Mercader, una joven de la burguesía catalana, que se había educado en un colegio de internas, la guerra española, con todo su horror, significó, como ella misma confiesa, una etapa de libertad al verse fuera de la férrea disciplina de las monjas. La muerte del padre y la situación

41. Siguiendo el texto memorialista, la familia Mercader al completo, una vez instalada en París, vivió un corto tiempo con el tal coronel, del que no da nombre, hasta que este se exilió en México.

42. M. Mercader (1980), 24.

43. Estos detalles se han conocido gracias a las memorias de la actriz María Luisa Merlo, hijastra de Vicky por el matrimonio de esta con su padre, el actor Ismael Merlo. VILLORA Gallardo (2003). 
familiar adversa habían propiciado su iniciación como actriz. Luego, ya en Italia, aquella chica pacata, sin mundo, y con poca cultura, se inició en la lectura de los autores a los que no había podido acceder por la nula educación recibida durante sus años de estudiante:

En las largas horas de espera que comporta el trabajo en el cine $[\ldots]$ no tenía más recurso que la lectura contra el aburrimiento [...] Leí a Víctor Hugo, Dickens, Dostoievski, a Jane Austen y a García Lorca [...] compraba los libros al azar [...] siguiendo el recuerdo de las insuficientes informaciones que me habían dado en el colegio ${ }^{44}$.

Tampoco podía presumir María en materia amorosa. Según confiesa, a su llegada a Italia seguía siendo virgen: "desde que se enteraron de lo mío [los compañeros] me trataban como a una educanda y como a una cretina" ${ }^{45}$. Su primer, y breve romance, sería un actor italiano: Osvaldo Valenti. A Vittorio lo conoció a los pocos meses de llegar. Fue una escena "incendiaria": "Vi por primera vez a Vittorio de Sica [...] en medio de un incendio $[\ldots]$ trabajaba en una película en Cinecittà, cuando se incendió el plató [...] también él estaba rodando, Rose Scarlate, su primera película como director" ${ }^{46}$.

Ese fue el comienzo de una relación, nada fácil, que duraría treinta años. A pesar de la diferencia de edad de la pareja, del estado civil de él (estaba casado con la actriz Giuditta Rissone), de las aficiones de Vittorio (sus variadas relaciones amorosas y con el juego), de los celos y el machismo del divo, que ella misma confiesa (por él dejó su profesión), sus destinos continuaron hasta la muerte del director. Sobre este particular, María escribe: "Vittorio era incapaz de admitir en las mujeres exigencias y derechos que en los hombres se le aparecían naturales" 47 .

La pareja tuvo dos hijos, Manuel y Christian, que siguieron la saga familiar. Por amor, Vittorio se hizo ciudadano francés para poder divorciarse de su primera mujer, con la que se había casado en 1933. Después de una boda en 1959, en México, unión no reconocida en la católica Italia. Tras su naturalización francesa, María y Vittorio se unieron legalmente en París en 1968. En México la pareja conoció a Luis Buñuel, de quien escribe: "si

44. M. Mercader (1980), 34.

45. Ibidem, 28.

46. Ibidem, 9.

47. Ibidem, 197. 
no hubiese sabido quien era, habría tomado a Luis Buñuel por un tranquilo señor burgués" 48 y también al director Emilio "Indio" Fernández, y a la famosa actriz Dolores del Río.

Tras la muerte de Vittorio retomó su profesión en varias películas: Juan, dirigida por Paolo Nuzzi (1976); Clarence, de Pasquale Squittieri (1984); La casa del sorriso, de Marco Ferreri (1988); Luces y sombras, de Jaime Camino (1988); La cuenta Max, dirigida por su hijo Christian De Sica (1991) o El lobo, dirigida por Carlo Verdone (1992).

\section{PALABRAS FINALES: LA HISTORIA CONTINÚA}

Carne de fieras, la película española, podría muy bien, como se ha escrito, proporcionar una buena historia para un nuevo guion de cine. También adelanta o, así nos parece, esa visión íntima, popular, que desarrollará el cine italiano posbélico. Guerra, como los neorrealistas, en cierta forma pone el foco en temas sociales, si bien, no busca sus personajes en la marginalidad, sino en el mundo de las variedades artísticas. A diferencia del neorrealismo sus actores son profesionales y algunas de sus escenas tienen ciertos rasgos surrealistas.

También los cineastas españoles en aquellos oscuros y autárquicos años -nos habíamos quedado fuera del Plan Marshall- intentaron desarrollar en los años 50 un cine similar, pese a la hostilidad y el peso de la censura franquista. El título pionero: Surcos (1951), película dirigida por José A. Nieves Conde, con argumento de Eugenio Montes y adaptación de Gonzalo Torrente Ballester y Natividad Zaro ${ }^{49}$, fue protagonizada por los actores Luis Peña y María Asquerino, que bordan sus respectivos papeles como campesinos desesperados que emigran a la gran ciudad ${ }^{50}$. No fue el único caso, pues años antes, durante la Segunda República, se rodarían algunas películas que cumplen a la perfección las características que Zavatini, Rosellini y Vittorio De Sica desarrollarían algunos años después, como es el caso del documental, financiado por el anarquista Ramón Acín, Las Hurdes, tierra sin pan, dirigido en 1932 por Luis Buñuel ${ }^{51}$.

48. Ibidem, 193

49. Una de las escasas guionistas de nuestro cine en aquella época. $C f r$. R. M. ${ }^{a}$ Ballesteros García (2011).

50. En 1957 Nieves Conde vuelve a la carga con El inquilino. La pareja protagonista: M. ${ }^{a}$ Rosa Salgado y Fernando F. Gómez.

51. Se financió con un premio de la lotería que ganó Acín, que comprometió a su amigo Buñuel para que realizara algo social. 
Por otro lado, no podemos dejar de citar, dado el contexto, a los cineastas españoles del llamado "cine de la disidencia": Juan Antonio Bardem (Muerte de un ciclista, 1955; Calle Mayor, 1956) y Luis García Berlanga (Bienvenido Mister Marshall, 1952; Plácido, 1961; El verdugo, 1963); y cómo no, al italiano Marco Ferreri, que dirigió tres grandes filmes del neorrealismo español: El pisito (1958), con Mary Carrillo y José L. López Vázquez; El cochecito (1960), de nuevo con López Vázquez y José Isbert y Los chicos (1959), con José Luis García y Joaquín Cascales Zarzo (las dos primeras con guion del inolvidable Rafael Azcona).

Por su parte, la historia de la película La puerta del cielo, condenada al olvido durante tantas décadas, fue revivida cuando el director, el siempre comprometido greco-francés Costa Gravas removió conciencias con su película Amén (2002), en la que acusaba al Papa de un silencio cómplice con la Alemania nazi y el Holocausto. Como respuesta, cierta prensa internacional (El Corriere de la Sera, Clarín o La Nación) sacaron a la luz la película de De Sica como prueba de que, con su realización, la Iglesia y su director habían salvado un buen número de judíos. Poco después, reclamado por el mismo tema, el director italiano Maurizio Ponzi, que ya había trabajado como asistente de Passolini, dirigía A luci spente (Las luces apagadas), estrenada en 2004. La acción se situaba también en 1943 y contaba la historia del rodaje de la película Redención, que había sido dirigida por Marcello Albani en los estudios Cinecittà y costeada por el Vaticano. Según la familia De Sica, este filme tenía evidentes similitudes con La puerta del cielo, a pesar de que su director, Ponzi, negó el hecho. Pero esta es otra historia que por sí sola merece más amplio tratamiento y al citarla aquí, como despedida, queremos dar relevancia a una producción que, aparentemente, había sido condenada en su tiempo al ostracismo.

\section{BIBLIOGRAFÍA}

Aguilar, Santiago y Cabrerizo, Felipe (2015), Vittorio de Sica, Cátedra/Signo e Imagen, Madrid.

Alberich Rodríguez, Ferrán (1993), Carne de fieras (1 ${ }^{\mathrm{a}}$ ed.), Filmoteca Española, Colección: Cuadernos de la Filmoteca, Madrid.

Aragón, Jabi (2012), "El cine libertario de 1936 a 1939. (Una experiencia de socialización única)", Libre pensamiento, 72, pp. 87-93.

Ballesteros García, Rosa M. ${ }^{\text {a }}$ (2011), Escritoras de cine (1934-2000): Galería de autoras, Universidad, Málaga.

Benet, Vicente J. (2015), El cine español. Una historia cultural, Paidós, Barcelona. Bertelli, Pino (1984), La dittatura dello schermo. Telefoni bianchi e camicie nere, Ed. Anarchismo, Catania. 
Caparrós Lera, José M. a (1981), Arte y política en el cine de la República (19311939), Universitat, Barcelona.

Casanova, Julián (1997), De la calle al frente. El anarcosindicalismo en España (1931-1939), Crítica, Barcelona.

Cruselles, Magí (1998), "El cine durante la Guerra Civil española (1936-1939)", Comunicación y Sociedad, XI, 2, pp.123-152.

De SicA, Vittorio (2015), La puerta del cielo. Memorias 1901-1952, Editorial Confluencias, Salamanca.

Díez Puertas, Emeterio (2002), El montaje del franquismo. La política cinematográfica de las fuerzas sublevadas, Laertes, Barcelona.

- (2003), "El cine bajo la revolución anarquista: Cine libertario", Historia 16, 322, pp. 50-101.

Domingo, Alfonso (2013), El enigma de Tina, Algaida Editores, Sevilla.

FERnÁndez, César (1995), "Del Neorrealismo y la revolución de las 'nuevas olas "”, Historia 16, 234, pp. 68-79.

FERnÁndez, Ezequiel (1998), Armand Guerra: Requiem pour un cinéaste espagnol, Documental, Zangra Productions, France 3 Sud, TV 10 Angers.

Fernández Ostos, María Teresa (2015), "La figura femenina en el cine anarquista durante la guerra civil: análisis y comparación de Barrios Bajos (1937) y Aurora de Esperanza (1937)", en R. CASAdo Mejía et al. (coords.), Aportaciones a la investigación sobre mujeres y género: V Congreso Universitario Internacional Investigación y Género, Universidad, Sevilla, pp. 493-508.

Gubern, Román (coord.) (1997), Un siglo de cine español, Academia de las Artes y las Ciencias Cinematográficas de España, Madrid.

- (2007), "La producción anarquista", en V. SÁnchez-Biosca (coord.), España en armas: el cine de la guerra civil española: ciclo de cine, Diputación, Valencia, pp. 29-34.

Guerra, Armand (2005), A través de la metralla. Escenas vividas en los frentes y en la retaguardia, 1937, La Malatesta Editorial, Madrid.

Harris, Mark (2014), Five Came Back: A Story of Hollywood and the Second World War, CanongateBooks, Edinburgh.

Heinink, Juan B. (1998), "Estado de alarma: el cine español de la II República durante el mandato del Frente Popular", en Actas del VI Congreso de la $A E H C$, Academia de las Artes y las Ciencias Cinematográficas de España, Madrid, pp. 133-144.

Hernández Girbal, Florentino et al. (2000), Los que pasaron por Hollywood, Biblioteca Virtual Miguel de Cervantes, Alicante.

Hubert, Rosemary (2004), Armand Guerra: un anarchiste dans la tourmente de la guerre civile espagnole, Mémoire DEA Espagnol, Nantes.

JARRY, Eric (2002), “Armand Guerra, cinéaste et anarchiste”, Le Monde libertaire, 1272, pp. 10-11.

Martínez, Josefina (2009), "Del rojo al azul. Las pantallas de las dos Españas", Espacio, Tiempo y Forma, Serie V, Historia Contemporánea, 21, pp.117-139. 
Mercader, María (1980), Mi vida con Vittorio de Sica, Plaza \& Janés, Barcelona. Miravitlles, Jaume (1977), El cine republicano español (1931-1939), Dopesa, Barcelona.

Monguillot Benzalon, Félix (2011), "Piruetas juveniles: génesis, desarrollo y fortuna de la película olvidada de Cesare Zavattini en España”, en Actas del XIII Congreso de la AEHC, Vía Láctea Editorial, Perillo (La Coruña), pp. 381-390.

Montero DíAz, Julio y Rodríguez, Araceli (dirs.) (2005), El cine cambia la historia, Rialp, Madrid.

Quintana Moraja, Ángel (1997), El cine italiano, 1942-1961: del neorrealismo a la modernidad, Paidós Ibérica, Barcelona.

Ríos Carratalá, Juan Antonio (2017), "El erotismo bajo las bombas: Carne de fieras (1936)", en M. GARCíA CARRIÓN (coord.), Cine, modernidad y cultura popular en los años treinta, Museu Valencià de la Illustració i de la Modernitat, Valencia, pp. 61-71.

- (2010), El tiempo de la desmesura. Historias insólitas del cine y la Guerra Civil, Barril \& Barral, Barcelona.

Ripalda, Marcos (2005), Neorrealismo en el cine italiano: de Visconti a Fellini, Ediciones Internacionales Universitarias, Madrid.

RoJAs, Luis Rodolfo (1993), "La triada cine, historia y guerra", Filmhistoria online, 3, 1-2, pp. 143-148.

Santos, Antonio (2017), Tierras de ningún lugar: utopía y cine, Cátedra, Madrid.

Sempere Serrano, Isabel (2010), "Las otras caras del cine negro: las versiones portuguesa y española de Tres espejos de Ladislao Vajda", Quintana. Revista de estudios do Departamento de Historia da Arte, 9, pp. 197-209.

Sorlin, Pierre (1996), Cines europeos, sociedades europeas 1930-1990, Paidós, Barcelona.

Stonor Saunders, Frances (2011), La mujer que disparó a Mussolini, Capitán Swing Libros, Madrid.

Torres, Augusto M. (1994), El cine italiano en 100 películas, Alianza, Madrid.

- (2004), Diccionario de directores malditos, Huerga y Fierro, Madrid.

Víllora Gallardo, Pedro Manuel (2003), María Luisa Merlo, más allá del teatro, Temas de Hoy, Madrid.

Zavattini, Cesare (2002), Straparole. Diario de cine y de vida, Instituto Valenciano del Audiovisual y la Cinematografía, Valencia.

\section{RECURSOS WEB}

hoycinema.abc.es/noticias/.../abci-carne-fieras-pelicula-maldita-201607312139.html https://www.filmaffinity.com/es/film960151.html www.agenteprovocador.es/publicaciones/la-pelicula-maldita https://fr.wikipedia.org/wiki/Carne_de_fieras 
florentinoareneros.blogspot.com/2012/12/carne-de-fieras.html historiasdearteyguerra.blogspot.com/2012/11/carne-de-fieras.html www.dedominiopublico.org/peliculas/carne-de-fieras-1936/ https://es.wikipedia.org/wiki/Vittorio_De_Sica decine21.com/biografias/vittorio-de-sica-16134 elcultural.com/blogs/el.../vittorio-de-sica-el-cineasta-de-la-dignidad-y-la-compasion/ http://ita.anarchopedia.org/Armand_Guerra 